Supplementary Figure 1 - The heat map and centroid plot of the ten hierarchal clusters of genes identified as being differentially expressed $(p<0.001)$ in the alcA::ypkA strain under repression (G1-10) and overexpression (T1-10) conditions when compared to the wild-type strain.

\title{
Cluster G1
}

0 -0 . 10 2065e32

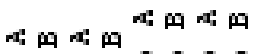

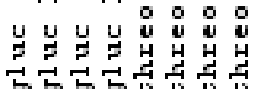

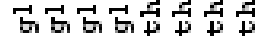

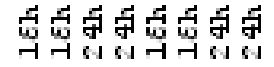
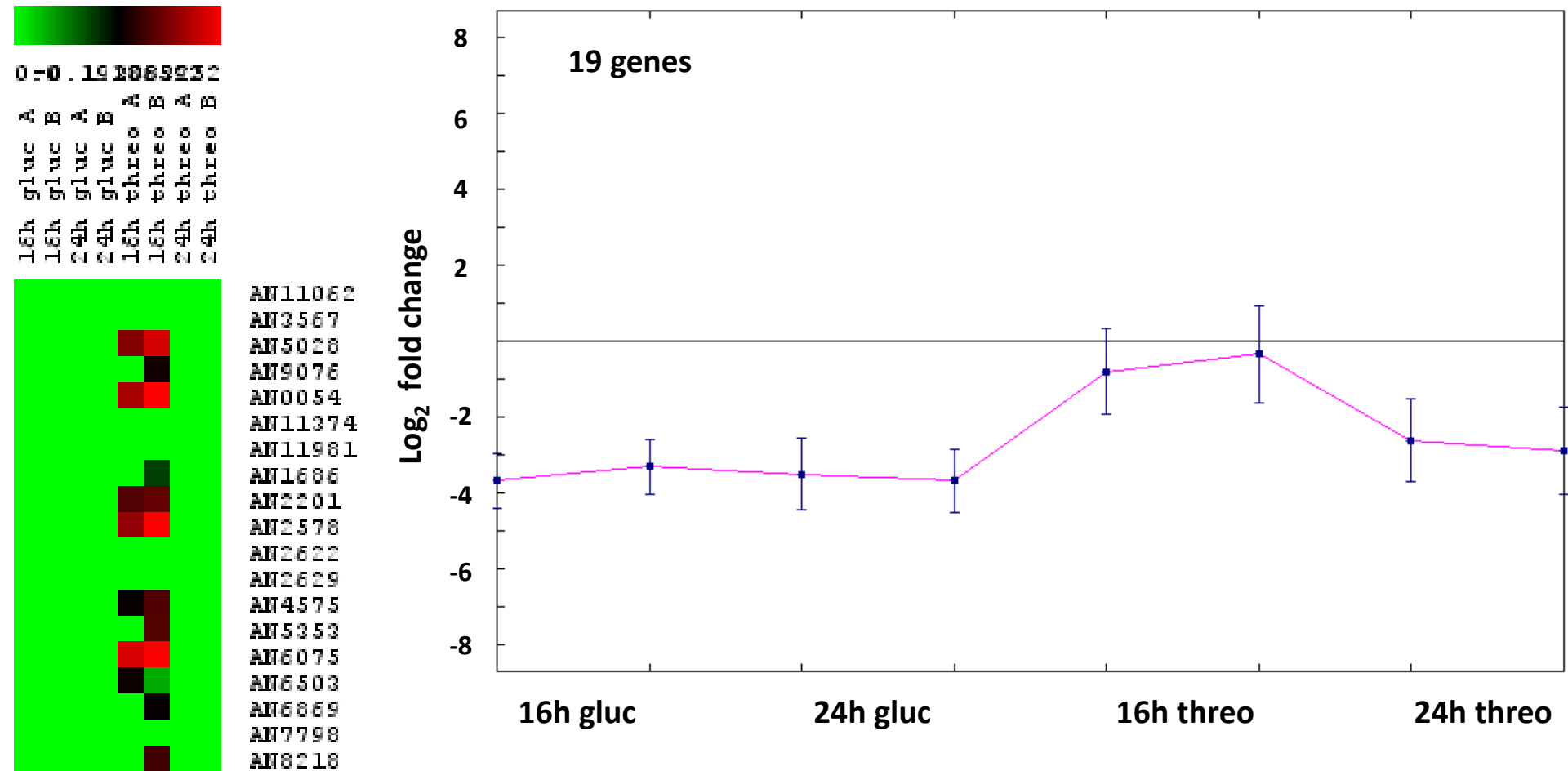


\section{Cluster G2}

\section{0}

$0=0.10$ 2085932

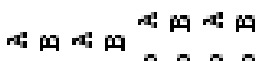

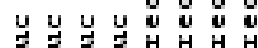

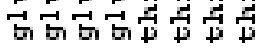

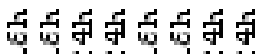
Нળ心Нળ心

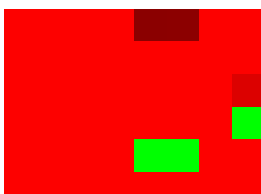

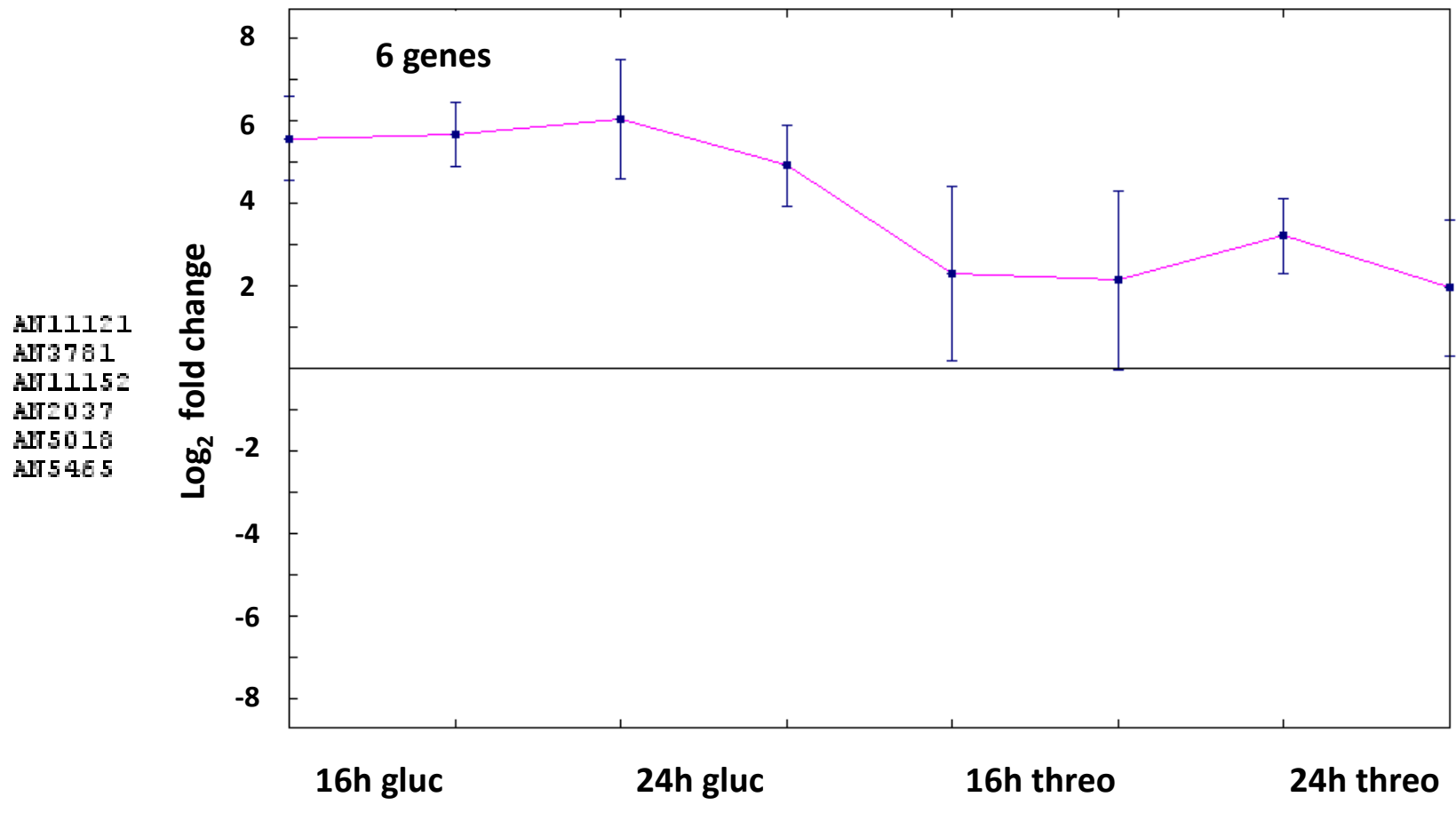




\section{Cluster G3}

$0=0$. 10 2065e3 2

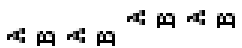

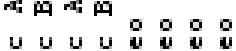

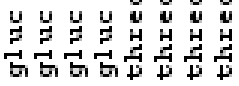

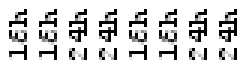

An8774

세도연

A115993

쇼은드

A.110 493

세11882

세드 588

AII11211

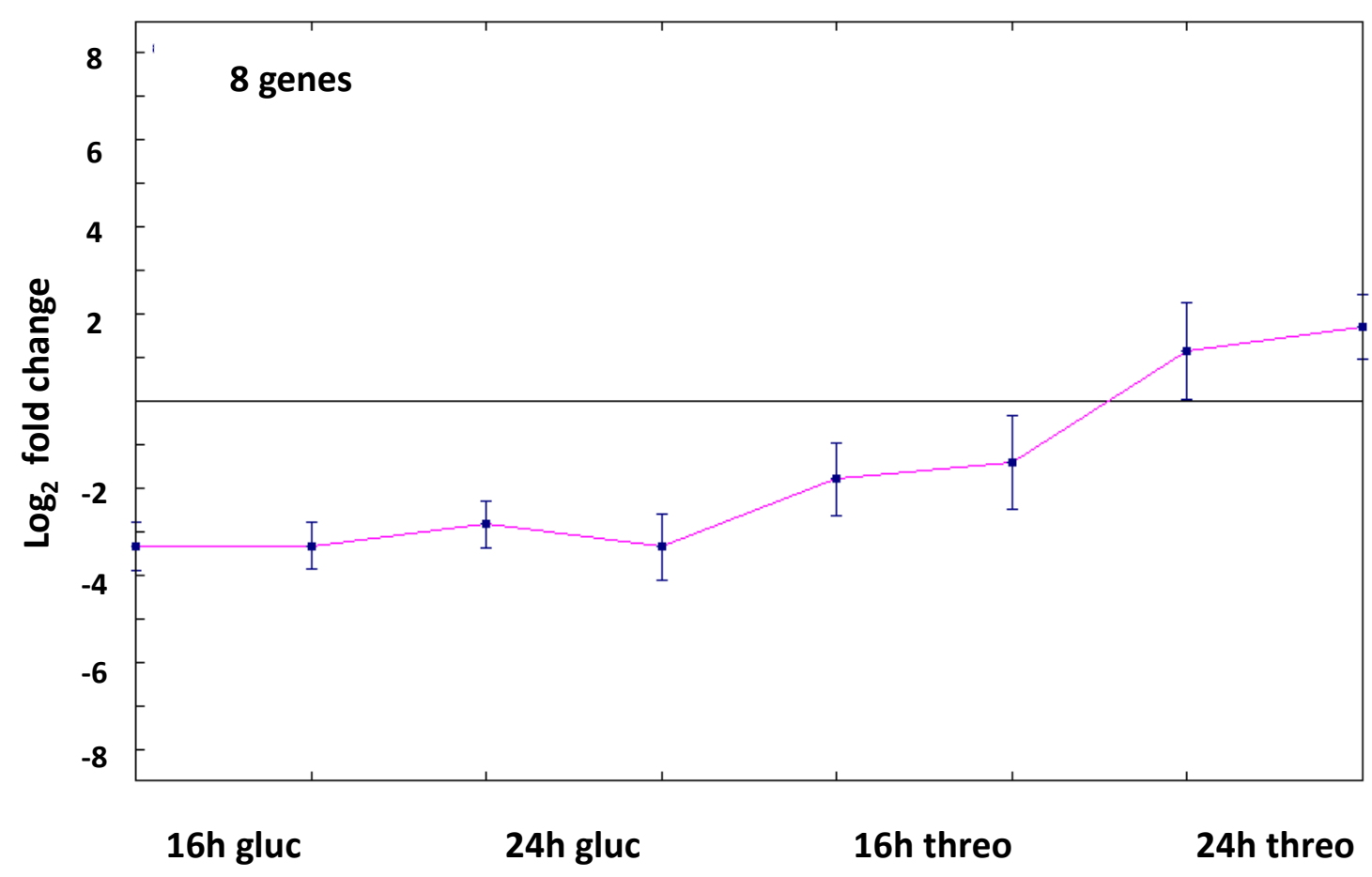




\section{Cluster G4}

0 -0 . 19 206se3

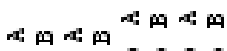

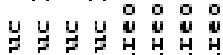

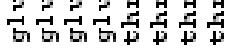

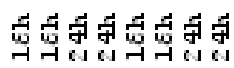

A116 586

Alto 461

AII 280

A11 3053

Aा16 172

A.117 320

시 750

110790

ג111079 0

All10935

AnII11149

AIㅣ는 5

Ant 2390

AIII 3641

AII 4642

A11 5033

A175033

세 5274

AII 6430

A116 770

Alt7 416

A117 594

쇼응

A118781

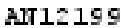

AाI 1619

ㄱำ 4

A173246

A115252

Alt 6135

게 6327

AlT6 642

AIII7 181

Al17389

Aㄴㅈ 3130

A1T3130

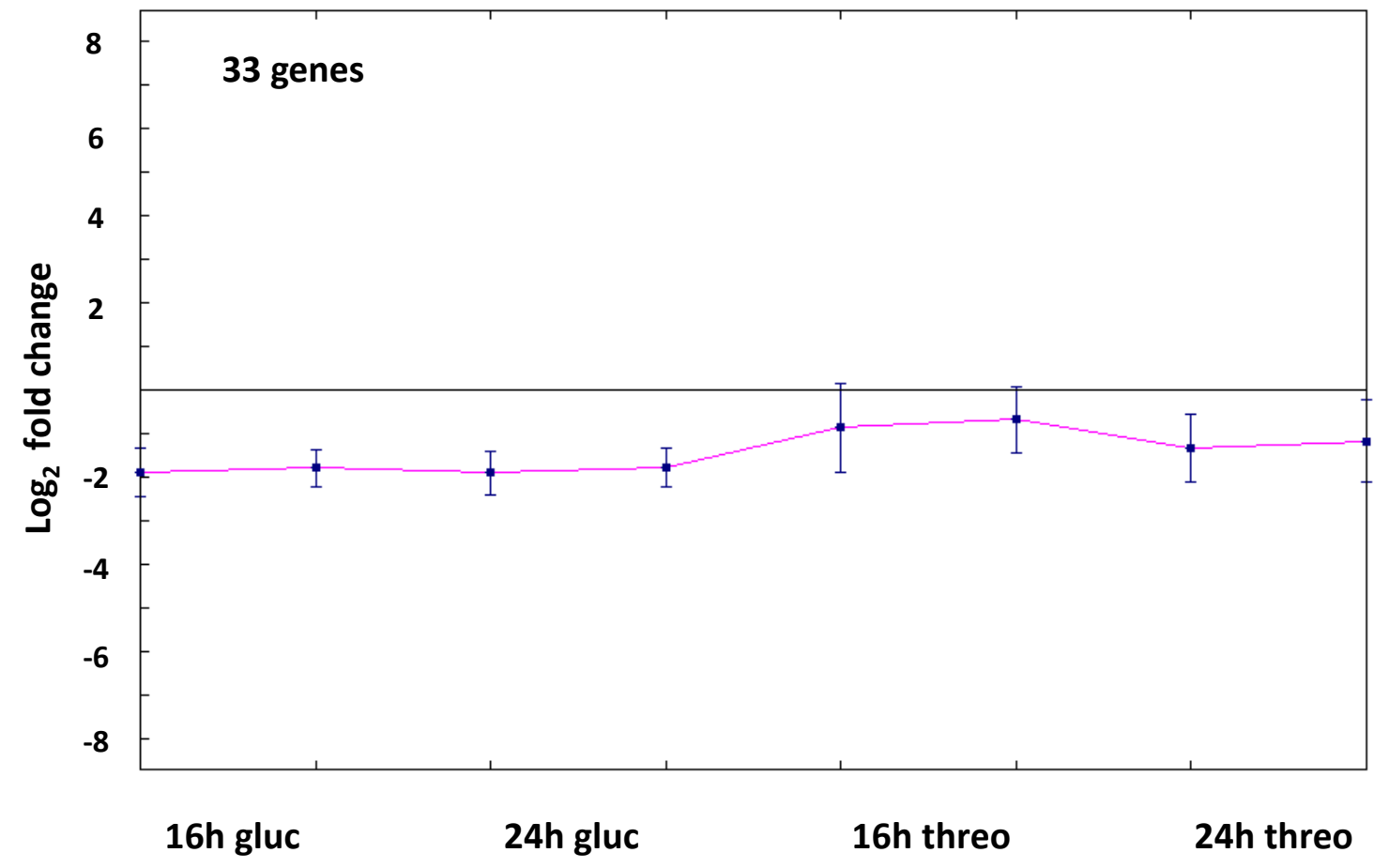




\section{Cluster G5}

0 -0 . 10 2065e3

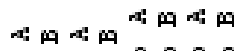

บ บ บ บ 유:

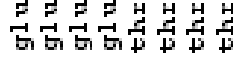

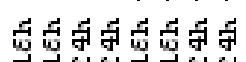
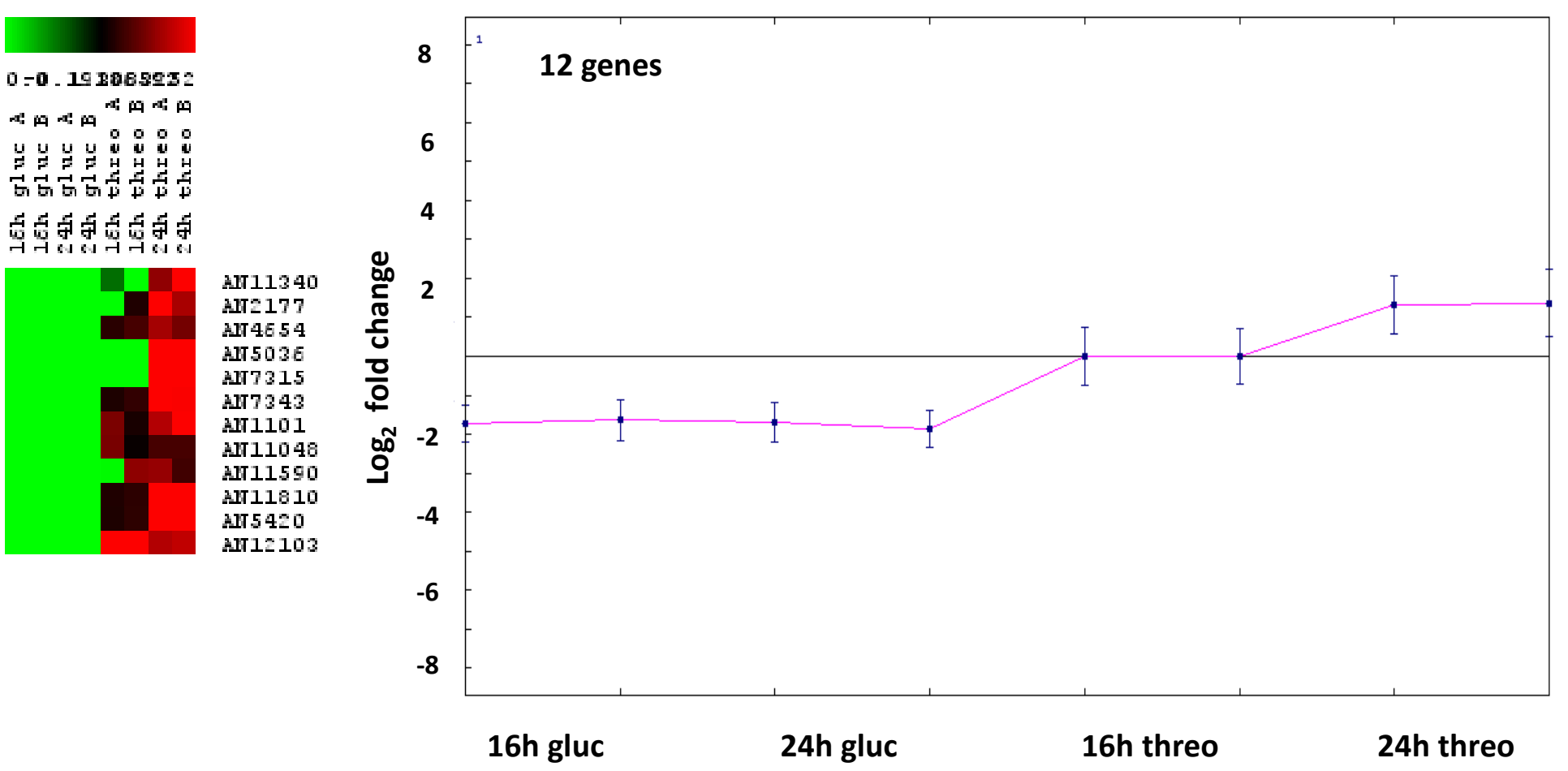


\section{Cluster G6}

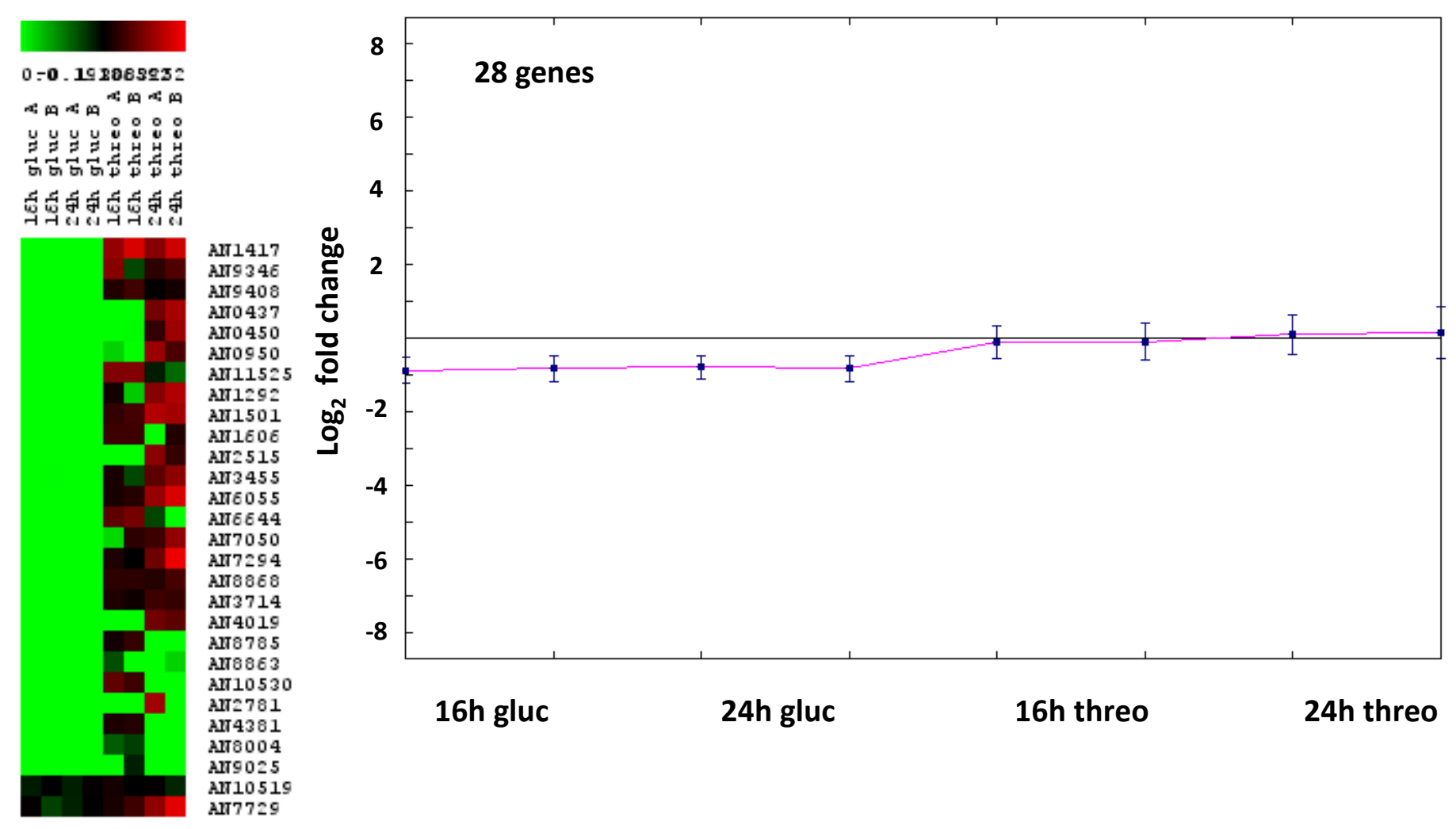




\section{Cluster G7}

$0=0$. 19 208593?

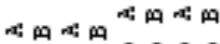

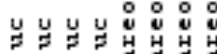

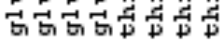

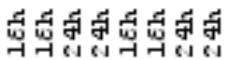
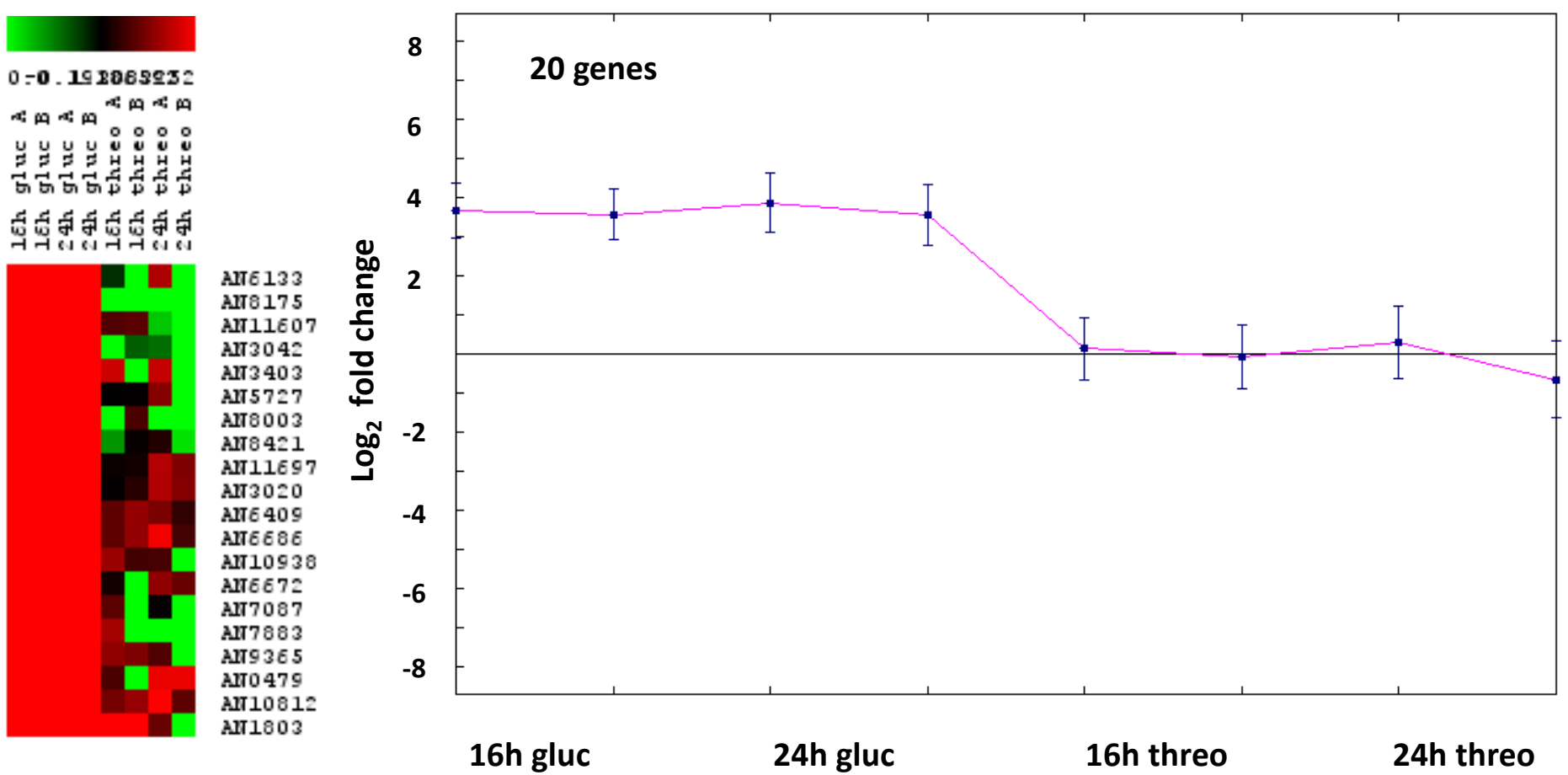


\section{Cluster G8}

\section{.}

. 10 2065e32

吅叫叫叫

บ บํㅇㅇ

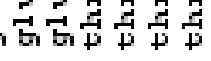

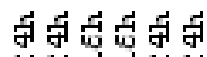

ज小

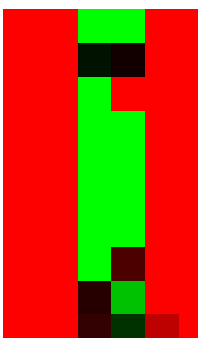

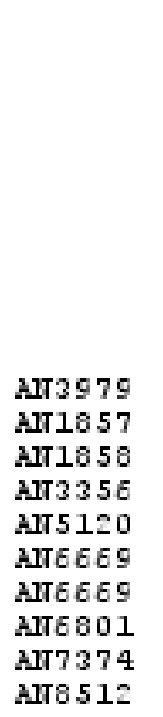

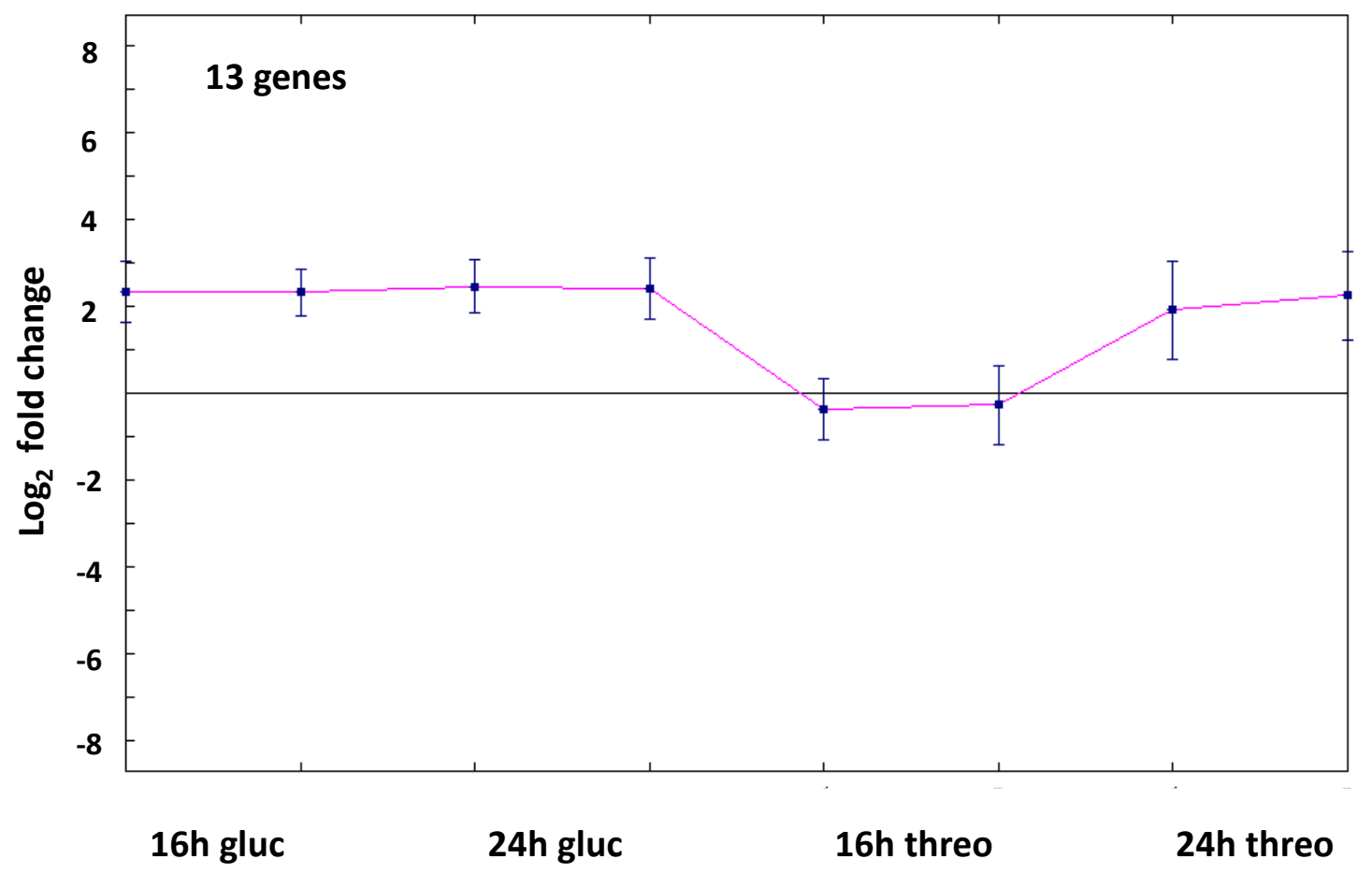




\section{Cluster G9}

0 -0 . 10 1085932

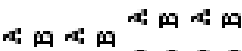

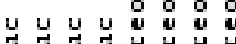

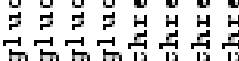

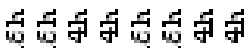

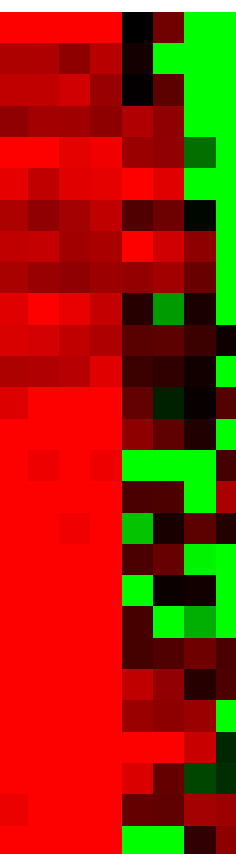

A.11 10424

세 6405

AกI 2864

Ant 5208

시 6386

쇼진 34

AIIT 7568

AnT 256

AnI 11022

세는 348

세즈 521

Alt 3057

AIIT 4257

치 6831

A17790 5

A1T8 578

Ant10196

AnT 1620

A1I 4767

A118819

Ant 2045

A117786

가8037

싱 738

All 4438

AII 3876

Alt 5633

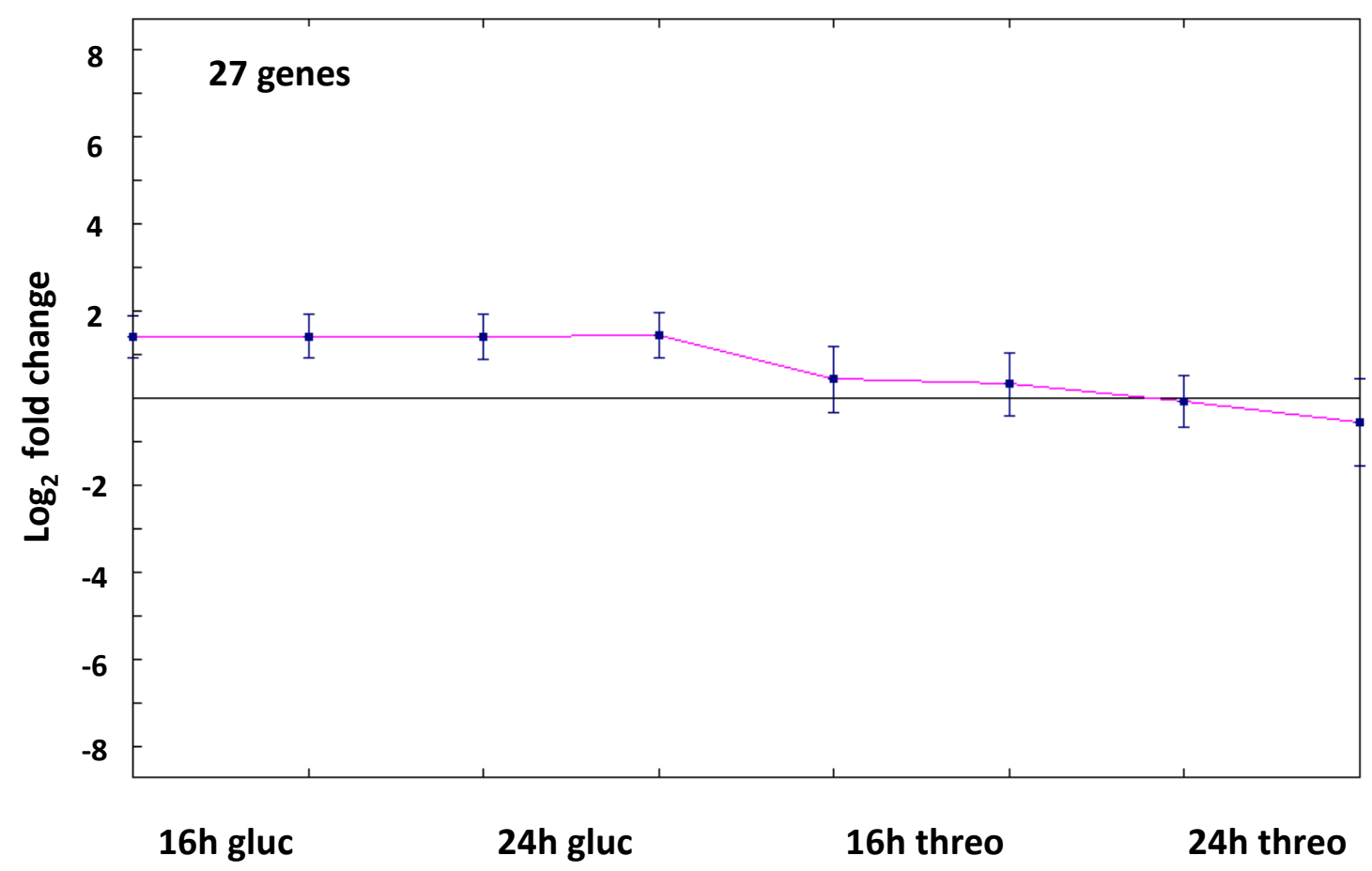




\section{Cluster G10}

0 -0 . 10 2085e3 2

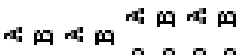
는

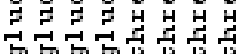

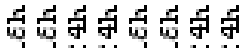

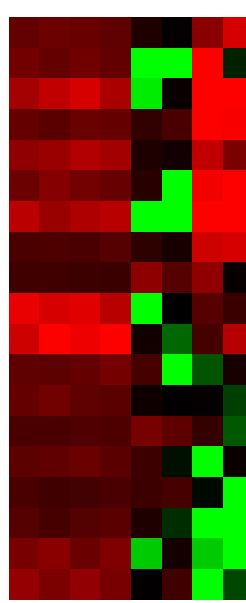

A1T8024

A1178775

A.112664

세 4002

쇼난 61

An1119 5

A.II1130

시 12050

AIIT 4052

AII 4824

섿8요

(170393

강 680

AnT10498

AII1168

AnT2058

2110885

15600

신ㄷㅇ

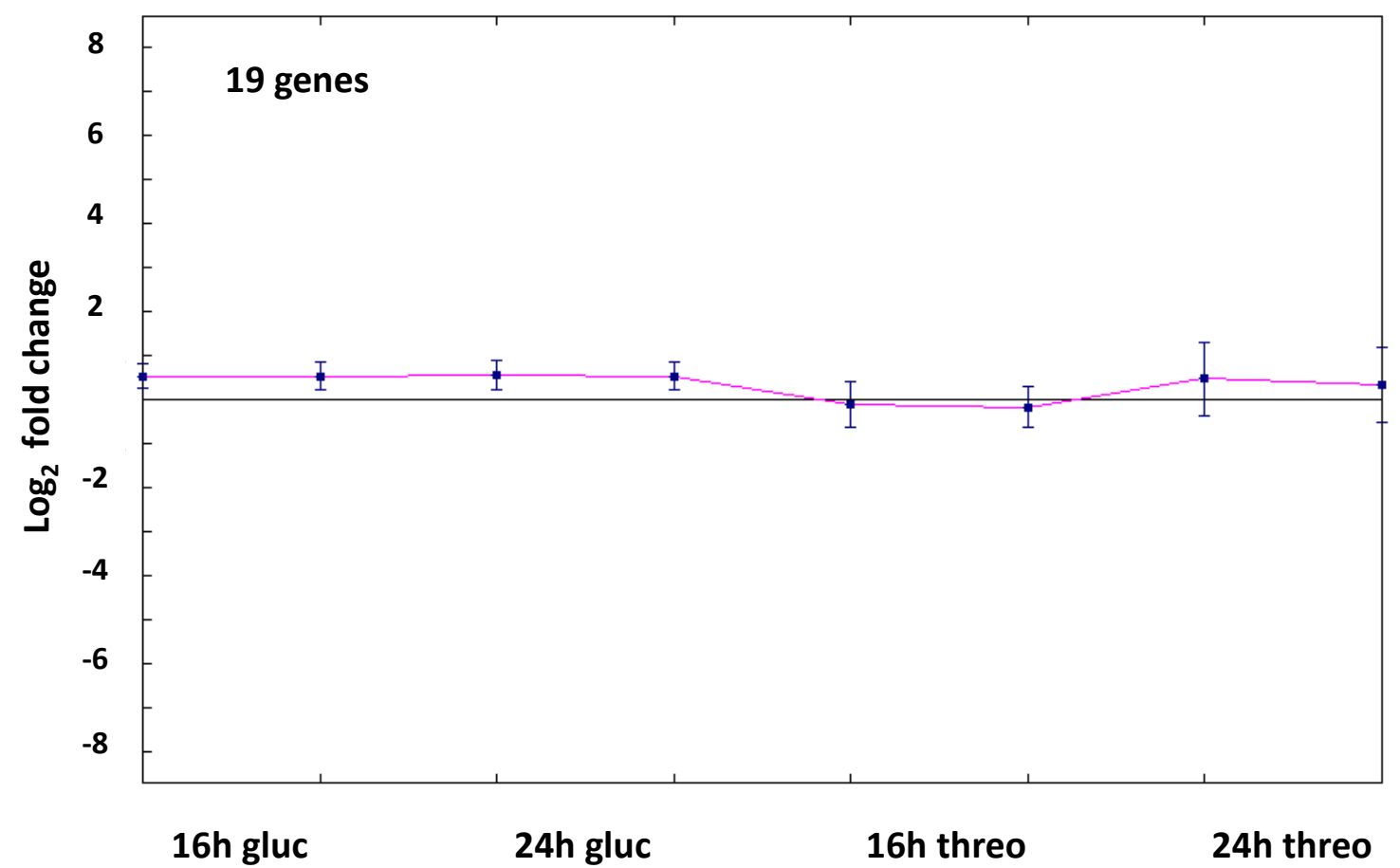




\section{Cluster T1}

0 -0 . Dอระระ593

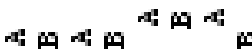

บ늘 U

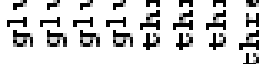

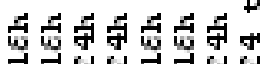

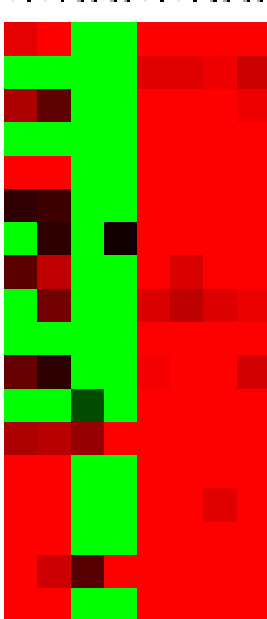

A11 11680

A.15 5650

Anto0g 4

All10620

Ant10042

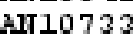

Alt10767

A1110945

쇼111368

AIII11976

A 1972

AnI 3181

A113928

A.15 5276

An616?

Ant 380

Altro009

ant9 500

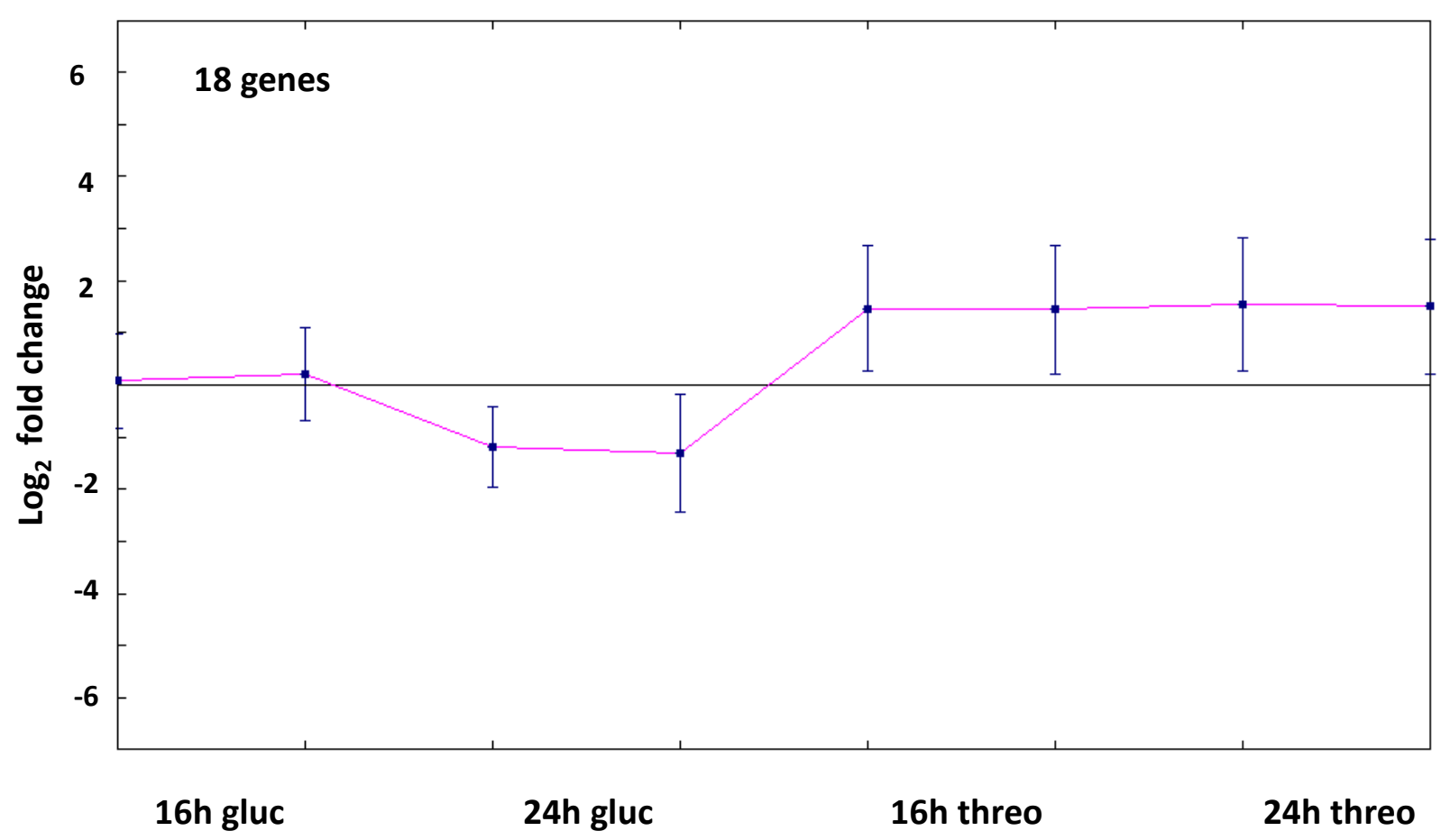




\section{Cluster T2}

0 -0 . Dดระรว593

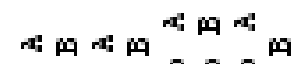

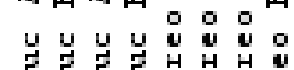

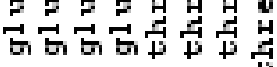

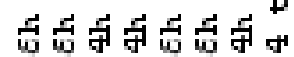
T)

Ant1723 AII 629 A1177 727

A1r7753

AIt8 445

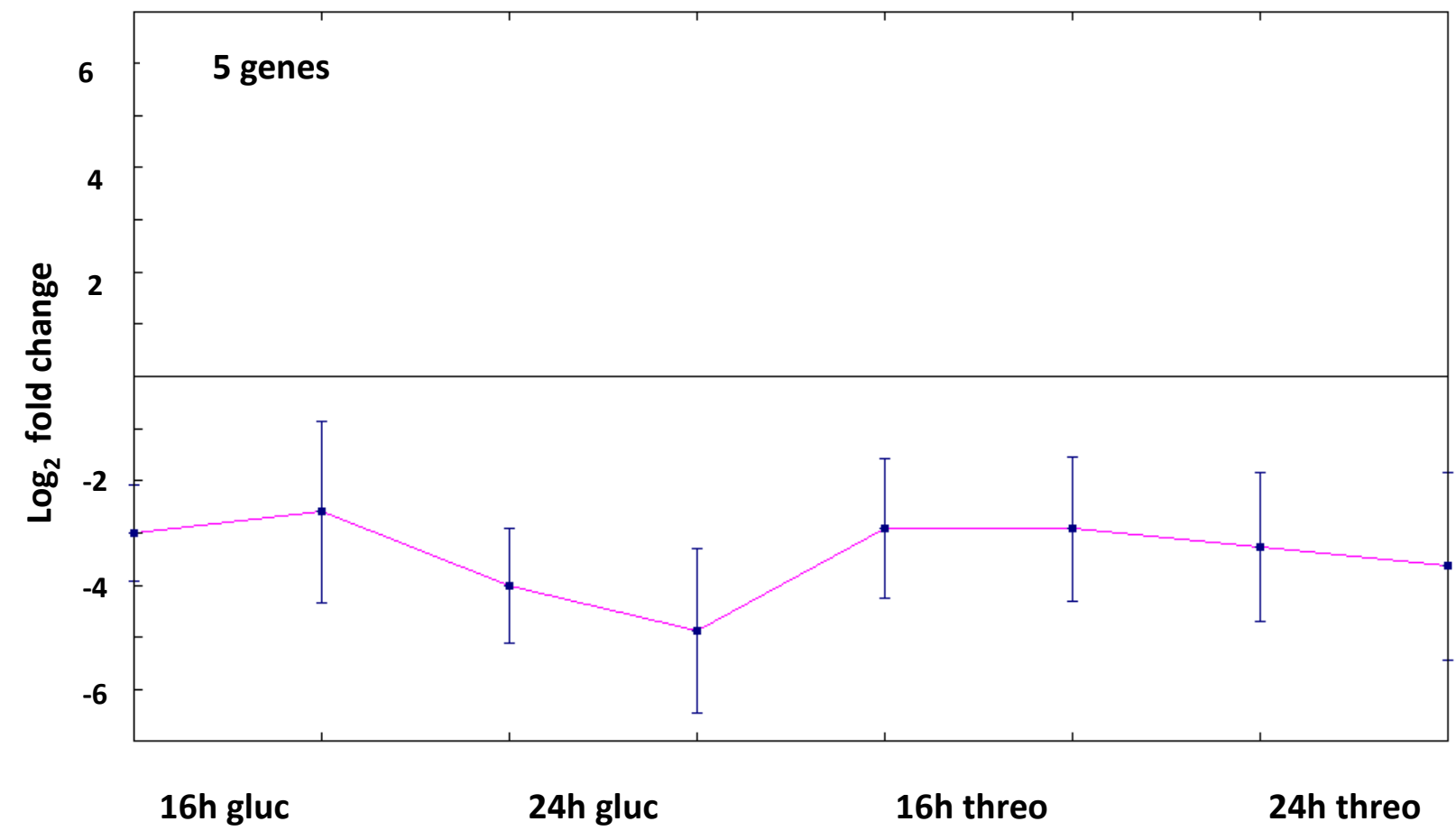




\section{Cluster T3}

0 -0 . จอระรร593

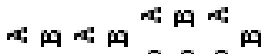

บ บ บ บ 운

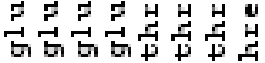

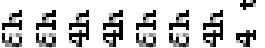

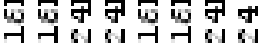

A.117894

A117893

Anto 149

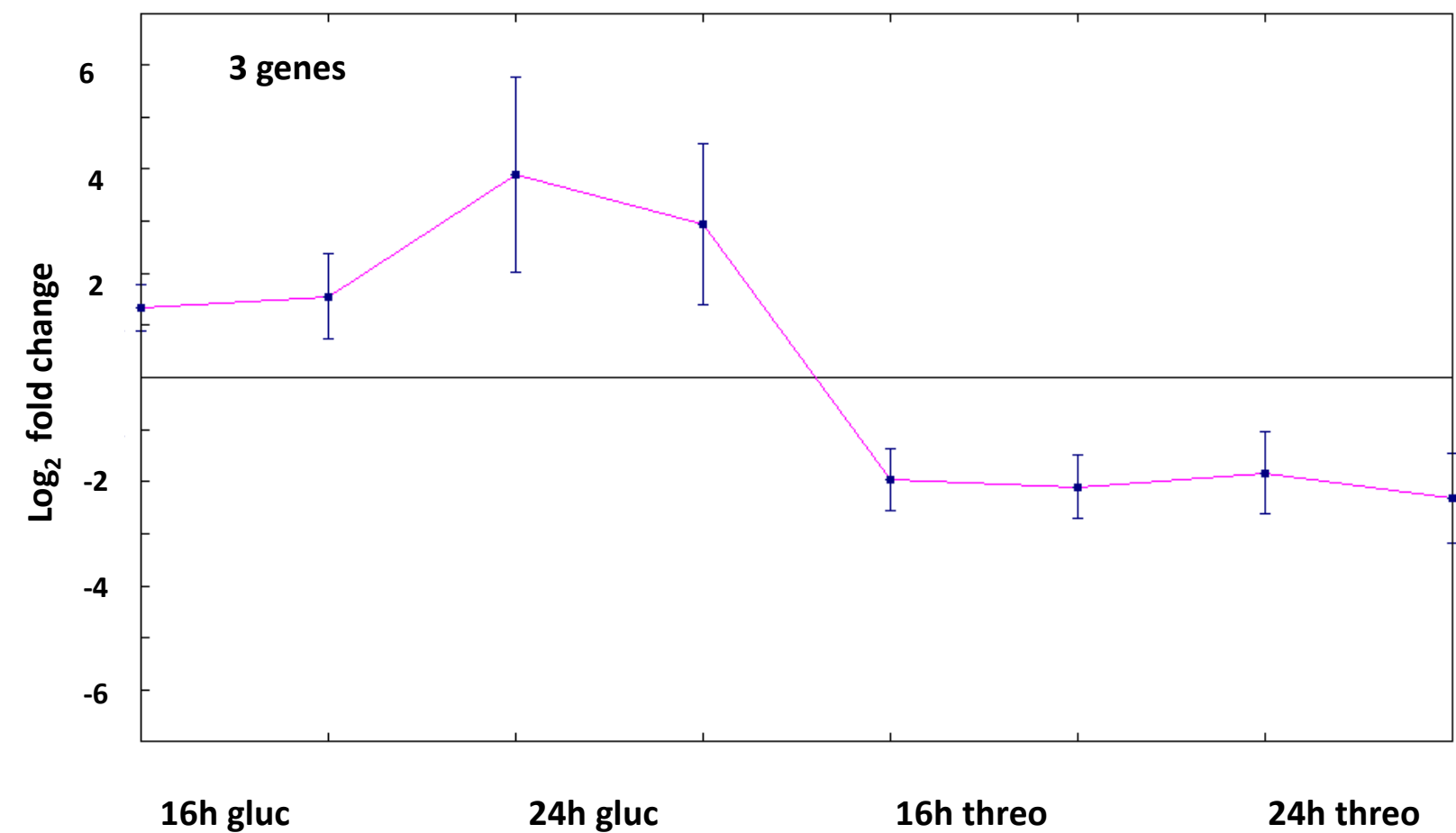




\section{Cluster T4}

0 -0 . Dดระรร593

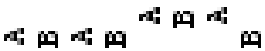

บ ب بِ

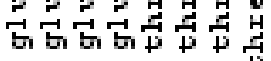

뎌뎌뎌뎜

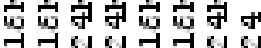

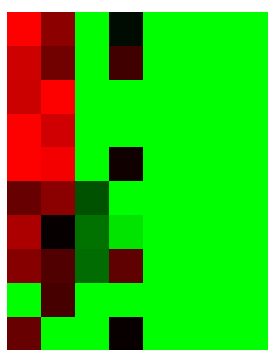

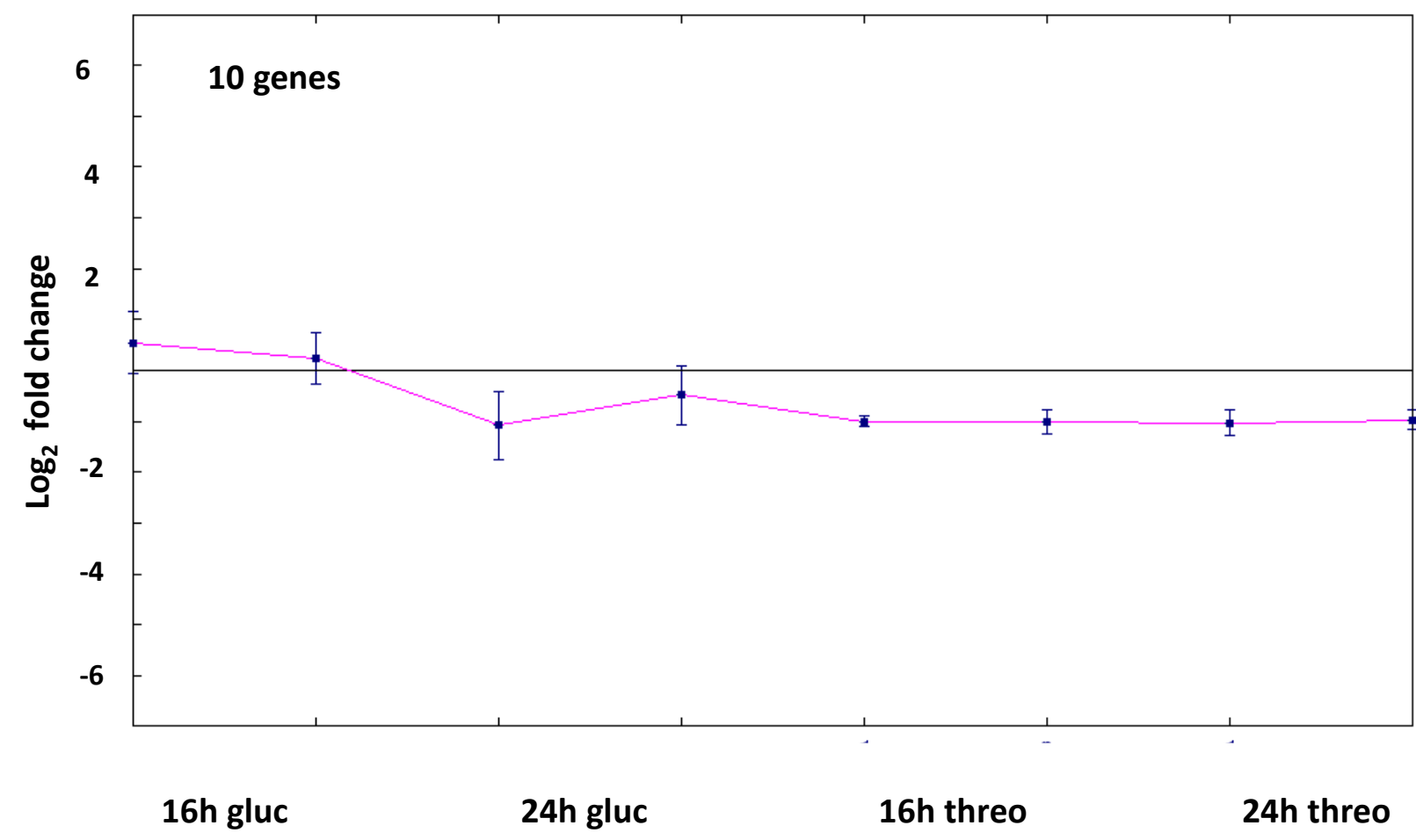




\section{Cluster T5}

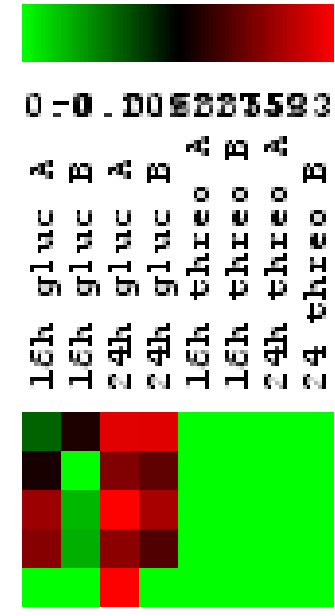

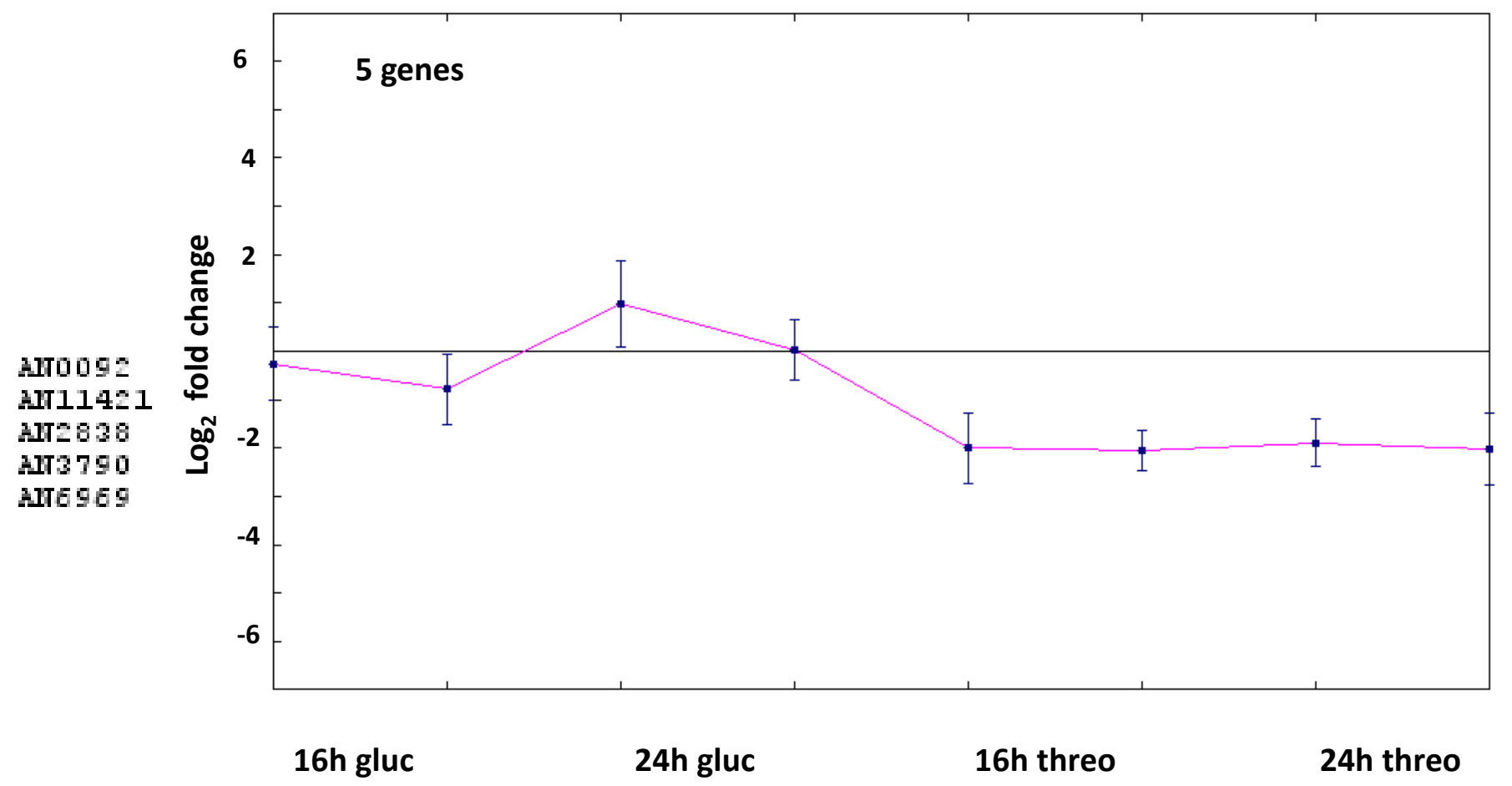




\section{Cluster T6}

0 -0 . Dดระร\$583

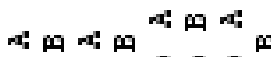

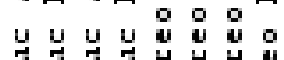

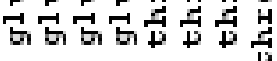

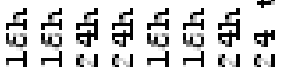

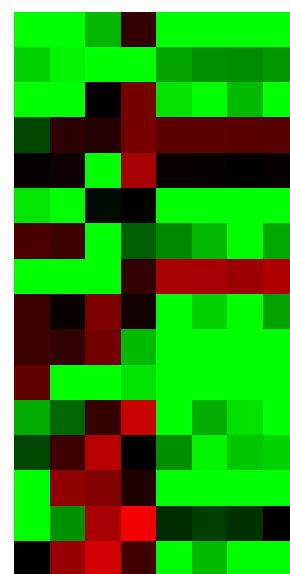

A1I 4069

A.11776

쇼는 446

Ant 210

Ant 698

A.IT 1245

Ant2896

세능 5

쇼준 375

Ant 4701

Ant 5536

Ant6064

Ant 580

Al1 9003

세즈2 293

A.1T6 189

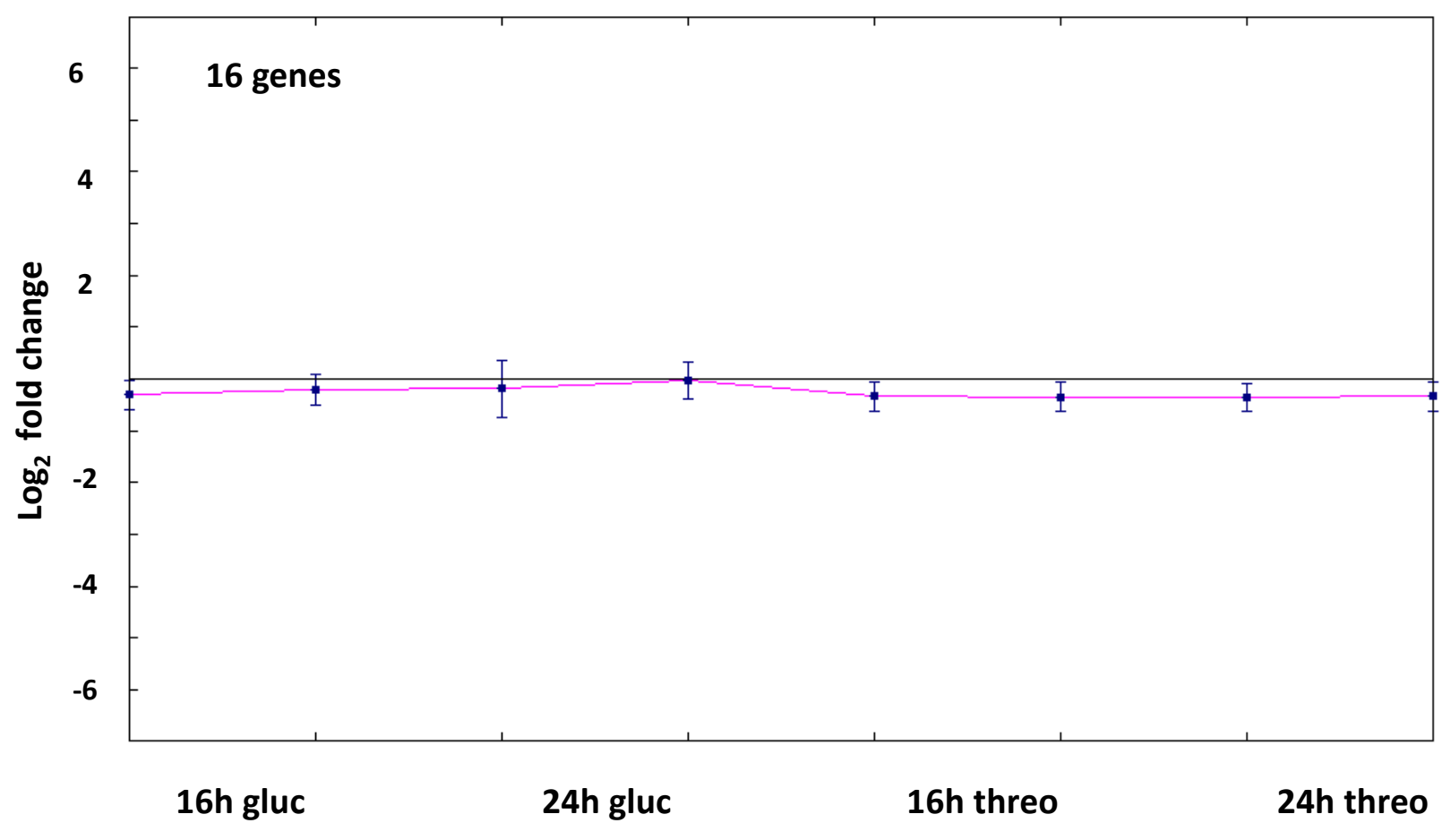




\section{Cluster T7}

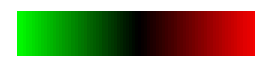

0 -0 . Dอระรว5ร3

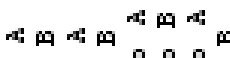

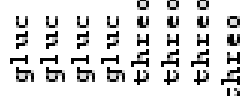

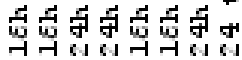

añ 1 ag

AlT2994

AlI 5408

AIT8006

Alr8370

A.1T8 422

AมाT8661

A1T8737

A.1T8890

AnT2941

세는 5

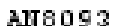

A.1T8670

AnIT 4394

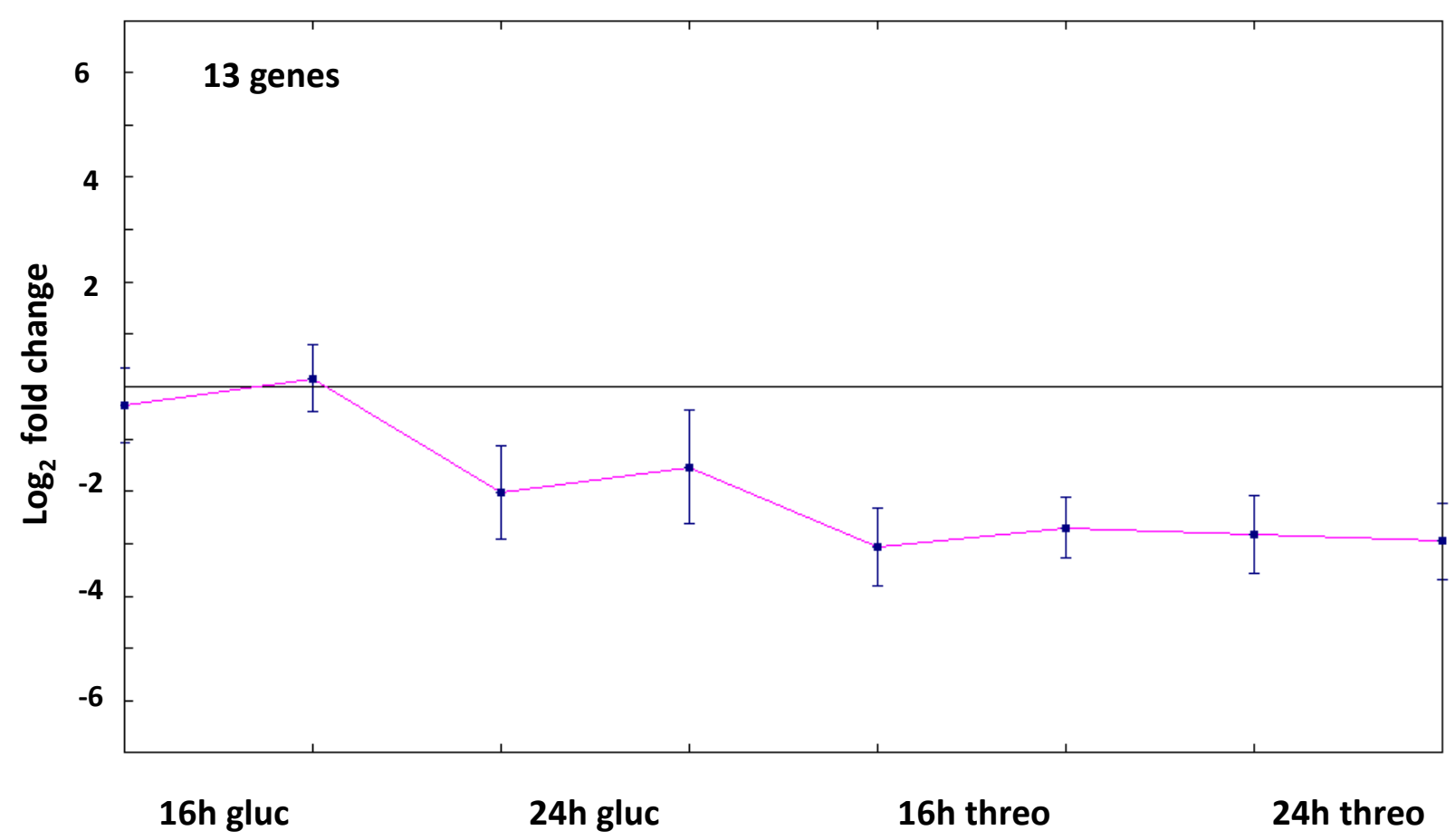




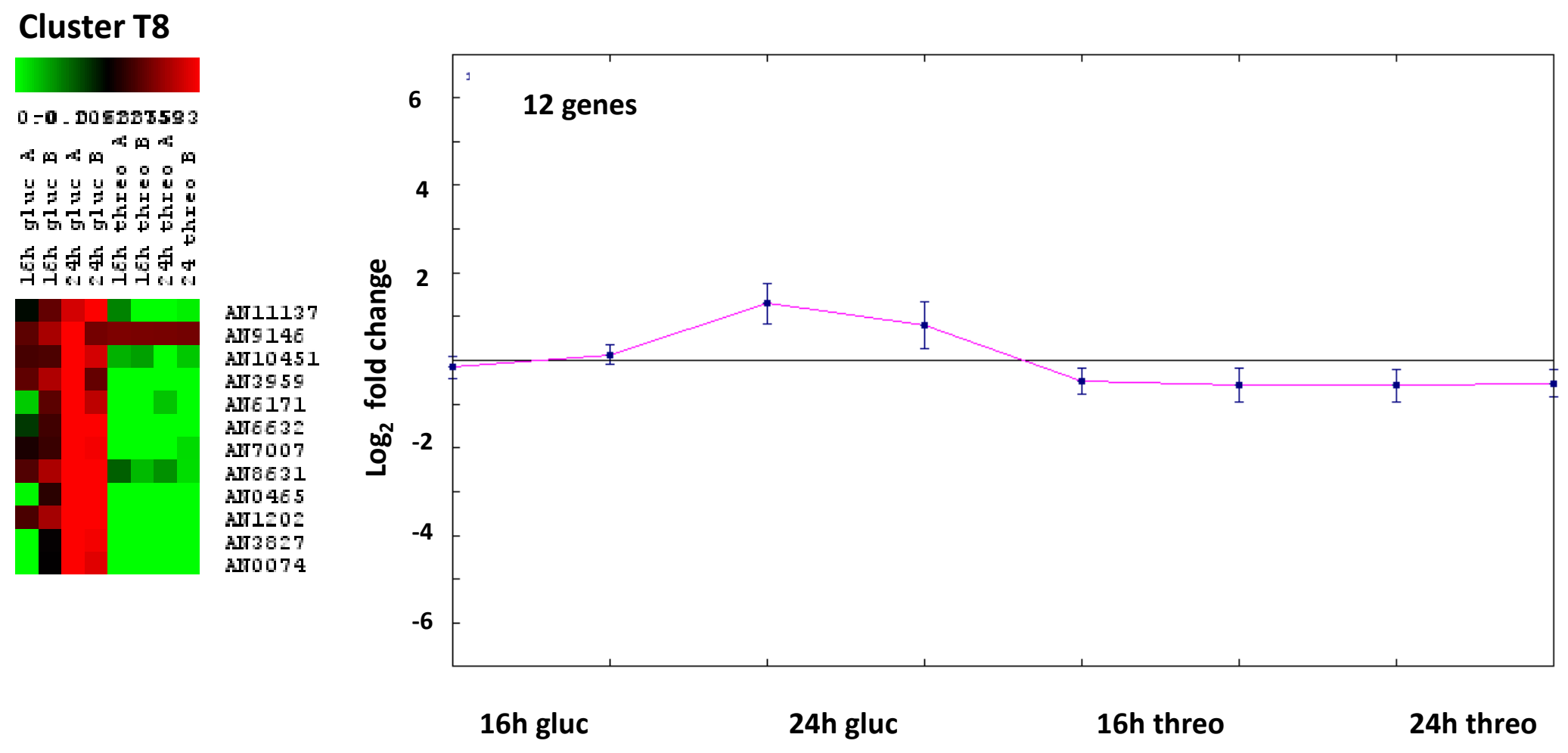




\section{Cluster T9}

0 -0 . จอระอร5ด

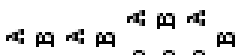

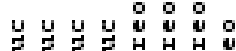

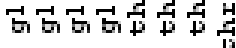

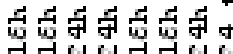

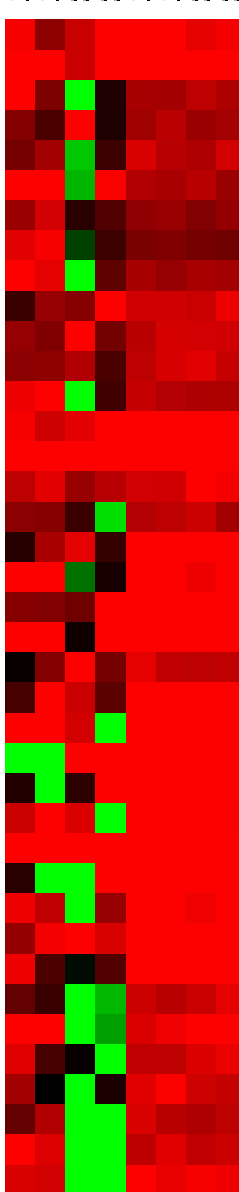

AnI 12017

Ant9 051

AnT 221

Ant 10800

Alt1 1907

AIIT 3505

AIIT3805

세구을

Ant4216

AlT4789

AII 4970

AII 5157

All7 482

AlT8177

Ant 608

AIT8681

Alro093

Allo178

쇼을 273

Ant1006

Alt1007

AIII 10773

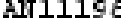

All1 11393

AIII11437

AnI 1825

AlI 2200

AIIT 4310

AII 4435

AIIT 5200

Ant5 5266

Alt 6617

AlI7 648

Ant1 12084

AlI12241

AIT 550

AnI 10404

AnI11126

AII 5107

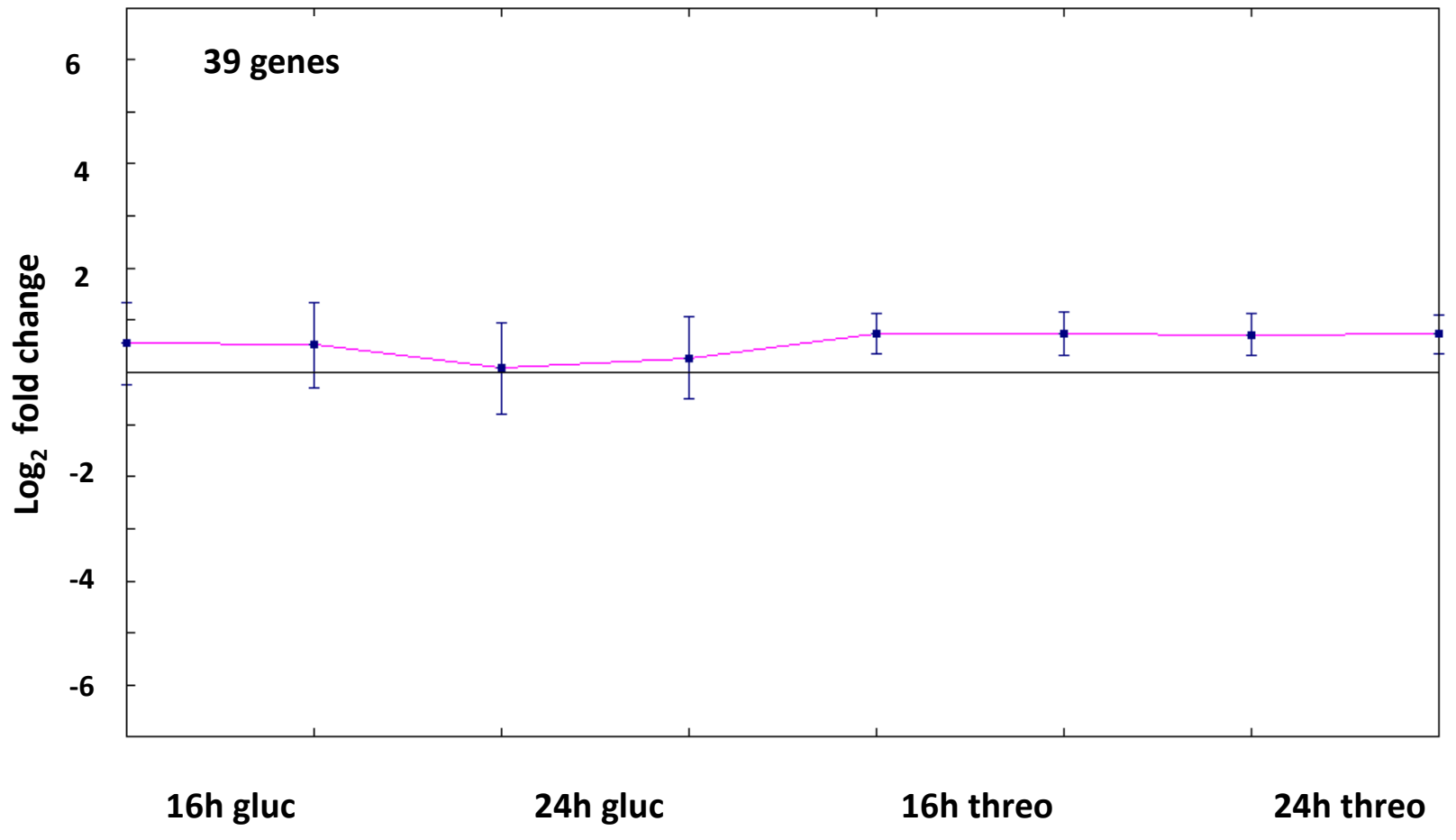




\section{Cluster T10}

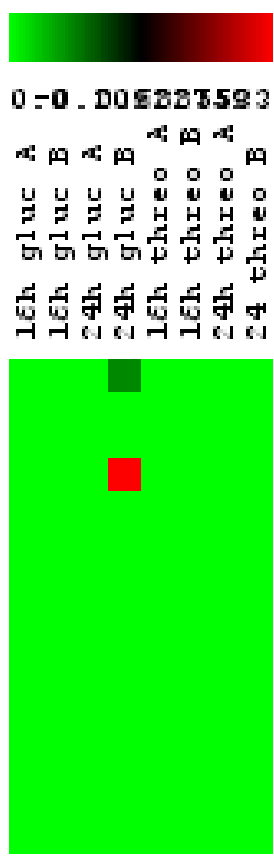

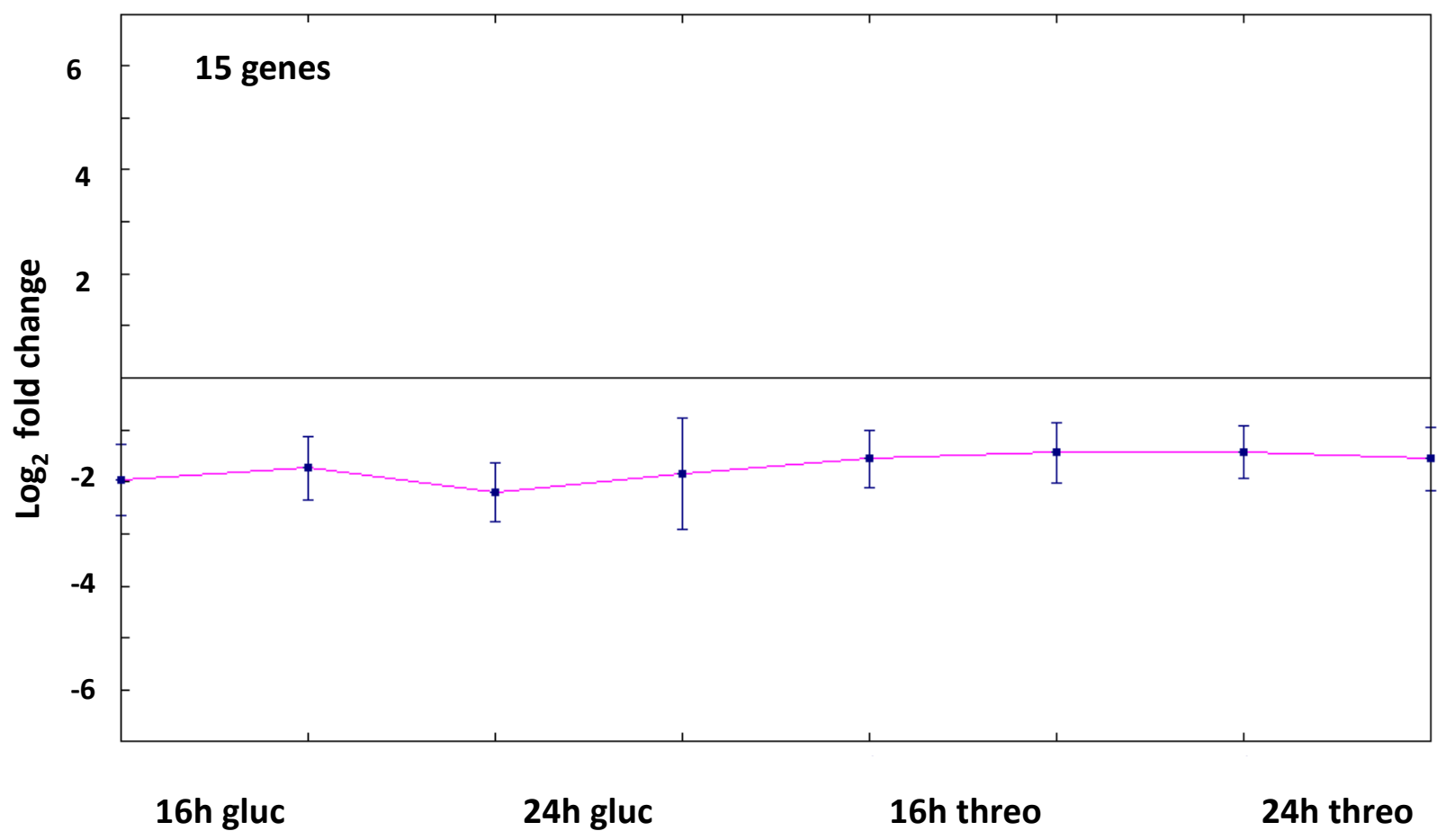

